\title{
Analysis of Core Value of Psychology in Management
}

\author{
guangli LUO \\ Postdoctoral Science Research Workstation of China Industrial Safety Research Center, Beijing Jiaotong \\ University, China
}

\begin{abstract}
Management is a science and technology associated with people. The subject, object and content of management are respectively people, human behavior, interpersonal relations formed by a variety of interests. Management behavior is the total work based on a predetermined objective, and various relationships carried out by executors (relationship between human and object, the people's relationship, and relationship between human and human itself) to coordinate and execute specific tasks. Psychology is a discipline studying human inner thoughts and behavior significance projecting outward. The coordination and the characteristic of communication of management are achieved by psychology. Management activity is essentially the practical application of psychological theory and skill, involving various branches of psychology. Effective management is valuable social activities which appropriately apply the essential functions of the various branches of psychology, combine execution of organizational behavior, aim to coordinate the relationships between the various stakeholders in order to achieve various predetermined development goals. Various coordination and implementation are based on understanding and communication, and psychology plays a core role in management, which makes every management activity possible and meaningful. Further exploring the value of psychology in management is not only conducive to the development of psychology, but also provides a more effective, flexible, and acceptable solution. This article explores the core function of psychology in the discipline of management, using interdisciplinary research methods and functional analysis, the research method of particularity on the basis of new era for management tasks, aiming to make more organizers and managers grasp the core strength of management through this research, that is, the skill of management psychology, so as to allow organizations to create more social wealth and make managers' work fruitful by using appropriate method. Meanwhile I hope that more management scholars and psychologists get new inspiration from the point of view of the paper, jointly promote development and prosperity of psychology and management. Moreover, I expect that we can make efforts to promote the continuous development of China's management practices and management psychology academic fields through the research, so that the exploration can produce a strong social and scientific significance both theoretically and practically.
\end{abstract}

KEYWORD: Management; Coordination; Flexibility; Core

\section{THE HISTORY OFAPPLYING PSYCHOLOGY TO MANAGEMENT SCIENCE}

Management is the product of post- World War II economic recovery and a stable social and political environment. Some intellectual white-collars joined the worker force, and the original mechanical management was replaced by another management mode including humanity. In the early 20th century, "the father of science management", F. Talor and Elton Mayo jointly promote the emergence and development of management psychology by "Hawthorne experiment" , making management psychology theoretical. Psychology involves traditional period of the field of management, primarily organizational change, leadership behavior, incentive problems, and organizational culture, etc. Management Psychology originated from United States and developed in the United States. In recent years, EAP and EAP are new breakthrough of applying psychology to management, greatly promoting the development of psychology and management science. The development and application of EAP and EAP raise the part of the organization function to the full range of organization that all activities from producing to ending in psychology are associated with and throughout the 
psychological value. Psychology plays a core role as head and think tank in organization.

\section{THE SOCIAL FUNCTIONS OF PSYCHOLOGY}

Psychology is separated from philosophy with a very high degree of social morality and humanity. Some abstract theoretical sources of psychology originated from philosophy. Most theories of philosophy are universal psychology. Psychology naturally has the functions of coordinating the society and carrying forward good value. I analyze from the following aspects.

\subsection{Functions on society}

The society is made up of various social groups and social relations, and interest structure and organization. Only finding the value standard and agreement we recognize and abide by together, we can move forward together. While the common value standard and the achievement of agreement and cooperation can carry on on the basis of understanding the inner thoughts of most people and the policy of altruism. This requires psychological theories and skills to understand what people think. If the value standard recognized by most of people goes on, such a society must be full of harmony, and people's well-being will be greatly enhanced. At the same time, psychologists also act as a caring role, making social care and positive energy always on trend. Society's requirement for the psychologists exists in a reasonable form, providing a lot of jobs. Psychology also provides intellectual support for political, economic and diplomatic activities.

\subsection{Functions on family}

The existence and continuation of the family, are achieved in highly harmonious psychological and physiological conditions, including marital affection, healthy pregnancy and scientific nurture, and emotional link and maintenance needing psychology to provide proper support. It needs family therapy when family relationship crisis happens. Psychological skills in family therapy put forward by Bert Hellinger and Virginia Satir greatly apply psychology to management of family relations, which produces outstanding effects. Nowadays many regions and organizations all over the world are learning how to use this family therapy.

\subsection{Functions on organization}

The symbiosis between organization members attributes to communication and recognition.
Psychology plays a core role in organization and management. The huge relationship in organization and management, such as the relationships between inner members in organization, administrators and subordinates, organization and external affiliates (clients, government administration section, suppliers), are formed by communication. Communication and psychology realize modern management, and make it develop greatly.

\subsection{Functions on individual}

Psychology makes a huge difference whether we act as an organization or a family member. If a person in the organization understands psychology, it is easier for him to understand the purpose of strategic objective of the organization and know how to realize this objective, to become a member who helps develop organization and achieve management benefits, to affect and drive others positively, which is beneficial for constructions of organization culture and personal promotion. A person with psychological quality also has its unique value to run the family business. Family conflicts will be conciliated, index of well-being boosted, which is conducive to physical and mental health of individuals and family members.

\subsection{Functions on health}

Mental health effects body greatly. Modern medical research shows that heart is a decisive factor deciding health, so all physical diseases ( except for accidents resulting in bodily injury ) are associated with heart directly and potentially. Supported by scientific knowledge of psychology, there are more guarantees for our health. Social Function becomes sounder, and we get physical and mental harmony, problems in real life reduced, which helps people get the best life quality and experience the happiness of life. The healthy development of above functions is the ultimate goal of psychological skill, as well as the ultimate goal of administrators. In conclusion, psychological skill is the practical discipline and core of management.

\section{THE MAIN SCHOOLS AND SKILLS OF PSYCHOLOGY}

Psychology has generated and developed in the west. It has developed many schools after more than 100 years of exploration, mainly including content psychology, conative psychology, structuralism psychology, mechanism psychology, behavioristic psychology, gestalt psychology, psychoanalytic psychology, Geneva School, Humanist Orientation and cognitive psychology. The influential schools are 
psychoanalytic psychology, behavioristic psychology and Humanist Orientation.

\subsection{Management involves major schools within psychology}

Every school of psychology has special function in a group of men. The major schools directly related to management are Humanist Orientation, behavioristic psychology, gestalt psychology and mechanism psychology. Organization transformation, leadership behavior, incentive problem and organization culture need psychological skill to support it. Humanist Orientation is represented by Maslow and Rogers, which stresses human dignity, values, creativity and self realization, and advocates proceeding from psychology and the nature of man. It mainly uses in organization, management and coordination, culture construction, human resources selection and training modules, target fulfillment, marketing and so on. Every school of psychology has special function in a group of men. The major schools directly related to management are Humanist Orientation, behavioristic psychology, gestalt psychology and mechanism psychology. Organization transformation, leadership behavior, incentive problem and organization culture need psychological skill to support it. Humanist Orientation is represented by Maslow and Rogers, which stresses human dignity, values, creativity and self realization, and advocates proceeding from psychology and the nature of man. It mainly uses in organization, management and coordination, culture construction, human resources selection and training modules, target fulfillment, marketing and so on.

\section{THE APPLICATION AND PROMOTION OF PRATICAL MODE OF PSYCHOLOGY}

Organization application psychology has a long history. Its effect is increasingly evident, and the forms is getting rich. For example, NLP, EAP and OAP are widely use, and their core theory and skill are psychology science. How to better apply flexible soft power of psychology to organizational management is of profound significance of reality and times. Nowadays, many fields such as cross culture, economic globalization, different voices of nation, international differences, environmental and ecological deterioration need a dialogue, while the foundation of dialogue is understanding and communication. Promoting practical psychological skill plays its unique and irreplaceable role. Realization of management value and personal happiness also makes a request for personal psychological quality. The cause of China's harmonious society especially needs practical application and support of psychological skill and plays a unique social value role in psychology.

\section{THE FUTURE OF PSYCHOLOGY IN THE FIELD OF MANAGEMENT}

Psychology has been gradually used and favored by people, and it has developed into comprehensive practical application and exploration of intellectual discipline, life education and philosophical system from a skill of knowing the face and adjusting emotion. It requires simple and specialized technique and discipline to solve complex social relations, and this specialized discipline is psychology. With the emergence of various social activities, psychological value in management science will become increasingly important.

\section{CONCLUSIONS}

Psychology is a discipline of inner soft power. All management techniques carry out through communication and coordination. Psychology meeting the functions of communication and coordination, is the core technology of management. Social needs is growing increasingly. There are two philosophies in China, one is "Being an inner sage so as to rule the outer world," the other is "Whether the environment is good or not depends on what you think in your heart," which reflect the importance of psychological factors, as well as the management results resulting from psychological factors. And it demonstrates the importance of attaching importance to mental ability. We hope more organizations and administrators in the organization strongly using psychological skills and theory, providing skill support for the society to create a wonderful internal world and external environment.

\section{REFERENCES}

[1] Shen Yue Research on Political Economics and Socialist Economy Economic Daily Press (Jul., 2007) Edition 1;

[2] Zhao Ran Employees Assistance Plan Science Publishing House (Jun., 2010) Edition 1;

[3] Wen Yuankai, Zhang Mao China Beauty 50 Beijing Publishing House (Jan., 2010) Edition 1; 